\title{
Exploring the Impact of Stress on Burnout: A Mathematical Model and Empirical Research
}

\author{
Cheng-Lin Jin, ${ }^{1,2}$ Ting Chen $\mathbb{D D}^{2}$ Shu-Yang Wu, ${ }^{3}$ and Yi-Lin Yang ${ }^{3}$ \\ ${ }^{1}$ School of Management, University of Science and Technology of China, Hefei 230088, China \\ ${ }^{2}$ School of Business, Anhui Xinhua University, Hefei 230088, China \\ ${ }^{3}$ School of Humanities, University of Science and Technology of China, Hefei, China \\ Correspondence should be addressed to Ting Chen; Chenting026@163.com
}

Received 3 May 2020; Revised 26 June 2020; Accepted 16 July 2020; Published 16 October 2020

Guest Editor: Shaohui Wang

Copyright (c) 2020 Cheng-Lin Jin et al. This is an open access article distributed under the Creative Commons Attribution License, which permits unrestricted use, distribution, and reproduction in any medium, provided the original work is properly cited.

Educational management and social psychology researchers have frequently suggested that job burnout and even turnover intention of college teachers can be induced by stress, which is an inherent part of fast-changing environments and advanced educational technology. However, studies about the contingency effect remain limited. We articulate the effect of role stress and technostress by integrating organizational behaviour and educational management literature. Particularly, this study tries to investigate the moderating effect of teacher agility and leader-member exchange differentiation on suppressing burnout. According to the job demands-resources model, we proposed that the negative effect of stress on burnout depends on the degree of agility and leader-member change quality (LMXD). A study of 271 samples supports the propositions. Specifically, the adverse effect of role stress on job burnout is strengthened by both employee agility and LMXD. We further elaborate theoretical implications on educational management, social psychology, and job demands-resources model.

\section{Introduction}

Job burnout refers to a series of negative mental experiences from chronic exposure to stress [1]. Prior job burnout literature was involved in social psychological research $[2,3]$ and organization behavior research [1]. Some studies started to explore the influencing factors and functional mechanisms in a special organization, such as in the healing domain $[4,5]$, and the accounting field $[6,7]$. Recently, some scholars emphasized teacher job burnout $[8,9]$, yet we still know little about how it occurs and how to constrain teacher occupational burnout.

Prior studies demonstrated that burnout was frequently associated with negative outcomes, such as turnover intention $[10,11]$, negative emotions $[12,13]$, poor task performance [14], and commitment to the organization [15]. Likewise, teacher burnout brings about psychological disorder [7] and emotional exhaustion [16, 17]. Teachers' beliefs, attitudes, and emotions affect teaching behaviors and students profoundly [18]. It is not hard to imagine how deep the despair of an "audience" full of eagerness and curiosity is when confronting an "actor" of emotional exhaustion [14]. Thus, it is extremely essential to be aware what factors account for the occurrence of burnout and it is necessary to investigate what factors can suppress the adverse effect

Burnout is an inherent part of stress [5], which will happen naturally while teachers are exposed to chronic pressure [15]. Some teachers deal with pressure successfully. Yet, for some teachers, burnout might be inevitable because they fail to successfully manage the stress [16]. To reduce and alleviate the negative effect, some researches explore the role of security-related stress on constraining burnout [19], which is verifies as an important factors affecting an employee's perception of burnout [20], including two dimensions, security-related role stress (SRRS) and securityrelated technostress (SRTS).

Prior studies emphasize that the efficacy of stress on burnout is contingent on the context. However, the contingent effect has only received scarce research attention. According to the job demands-resources model [21], 
security-related stresses are considered as "job demands" and leader-member change quality (LMXD) and teacher agility as "job resources." Thereby, we examined the contingency effect of LMXD and teacher agility on the role of security-related stress in suppressing teacher job burnout.

Thus, our study makes several contributions to psychological research and to education management literature. First, we extend the JD-R model, and we provide a more comprehensive understanding on the efficacy of the stress on teacher burnout that is moderated by the value of teacher-subjective effort and the leader-member relationship. Second, we remind teachers and their administrators of potential countermeasures and policies based on different kinds of personal characteristics and interpersonal relationships. Our study sheds a new light on the differential coping strategies in constraining job burnout under various types of stress that teachers suffer from.

\section{Theory and Hypotheses Development}

The JD-R model was developed to perceive the causes and consequences of burnout. Reference [22], which was first raised by Evangelia Demerouti in Journal of Applied Psychology. This theory further indicates two types of working conditions: JDs (job demands) and JRs (job resources). JDs are regarded as "negative factor" [21], which refers to the physical or psychological aspect of the job, and JDs are frequently related to the physical and/or mental costs. In addition, JRs are viewed as "positive factors" [21], which refers to the physical or mental aspect of a job, and they contribute to accomplish work targets, reducing JDs, or aspects relating to physical or physiological expenses and promoting personal working performance.

In our study, security-related stresses correspond with JDs' definition, which take up teachers' precious time and efforts. Meanwhile, teacher agility and LMXD pertain to the concept of JRs, which are beneficial for teachers in order to gain necessary resources and make right decision to complete tasks and accomplish targets. Inherent in the definition of JRs is the assumption that JRs may buffer the influence of JDs on job burnout [23]. Teacher agility and LMXD, which are types of JRs, can contribute to prevent and reduce burnout [12].

Our study develops a mathematic model, and the equations of teacher job burnout $(T J B)$ can be written as equation (1) [24]. SRRS and SRTS are considered as antecedents of $T J B$. Teacher agility (TA) and leader-member exchange differentiation (LMXD) indicate the moderating effect on the impacts of TJB. Age, Edu, Acat, and Ole are demographic variables. Based on the job demands-resources model, we try to achieve these following research targets: (1) to elaborate the SRRS and SRTS as essential antecedents to understand teacher burnout; and, specifically, (2) to explore moderating variables changing the extent of efficacy to which SRRS and SRTS impact on teacher burnout.

$$
\begin{aligned}
\text { TJB }= & \alpha+\beta_{1} S R R S+\beta_{1} S R T S+\beta_{1} L M X D+\beta_{1} T A \\
& +\beta_{1}(S R R S * L M X D)+\beta_{1}(S R R S * T A) \\
& +\beta_{1}(S R T S * L M X D)+\beta_{1}(S R T S * T A)+\beta_{1} \text { Age } \\
& +\beta_{1} E d u+\beta_{1} \text { Acat }+\beta_{1} \text { Ole }+\mu .
\end{aligned}
$$

2.1. Role Stress, Technostress, and Job Burnout. Burnout is a condition where an employee's physical, emotional, and mental energies exhaust or run out [25]. There is a strong connection between pressure and burnout [26]. Teacher burnout is consequent when exposed to chronic pressure or when there is a lack of job security [10, 27]. Severe occupational stress may obsessively exhaust teachers' energy and related JRs and eventually result in a severe status of occupational burnout $[15,28,29]$.

Security-related stress is divided into two concepts, security-related role stress (SRRS) and security-related technostress (SRTS) [20]. SRRS is workers' response to the situations where multiple roles are provided [20], which is associated with poorer decision-making [4]. Teachers frequently have to do a lot of work besides teaching and scientific research, e.g., the administrative task [25, 29]. Teachers experience role stress and are consequently unsure of their superiors' expectations and how they will judge the outcomes of their decisions. Teachers will "hesitate to make decisions and will have to rely on a trial and error approach." Teachers with ambiguous roles would waste more time in struggling to define and understand their own roles, which is bad for decision-making and problem-solving [26], resulting in increasing job burnout.

SRTS is "a kind of modern social disease for technology inadaptation," when the new technologies cannot be mastered and applied while working [20]. The lack of applying various technologies into educational environment has been considered as a key obstacle to their development [25] and teachers' capability of integrating the technology into their daily pedagogical work is beneficial for personal development and improvement [30]. More and more teachers are increasingly dependent on education-related technologies. However, at the same time, they are inclined to feel more stressed in a situation where various education-related technologies emerge successively and change rapidly [31]. Thus, as teachers strive to change conventional occupational practices and habits [32], it is inevitable that teachers will experience SRTS, which results in losing confidence and missing the previous catching-up opportunity through mastering educational technologies [20, 32], resulting in increasing job burnout. Therefore, we propose the following hypotheses.

(i) H1a: SRRS is related to teacher burnout positively.

(ii) H1b: SRTS is related to teacher burnout positively.

2.2. Moderating Effect of Teachers' Agility. Employee agility, a vital job resource, means a competence to respond promptly and accurately to variation $[33,34]$ and avail 
themselves of chances emerging from the changes. When encountering role stress, teachers with high agility will actively seek for solutions and leader support to break through the role dilemma and make decisions effectively and efficiently [35]. Meanwhile, those teachers with high agility are more adept at capitalizing on an emerging chance, in the ever-changing situation of education-related technologies [36]. Agility adapts teachers to ever-changing technological environments and avails them to modify themselves to better adapt to them. Thus, agility is beneficial for teachers to function efficiently when they are under technostress [37].

Drawing on the JD-R model [23], we propose that teachers with a high level of agility will weaken the efficacy of role stress and technostress, leading to a suppressing of teacher burnout. Therefore, this study attempts to explore the moderating effect of teacher agility on the link of security-related role stress and technostress on teacher burnout. Based on the agreement above, when teacher agility is high, role stress and technostress are less salient in intriguing burnout. Therefore, we propose the following hypotheses.

(i) H2a: the negative efficacy of SRRS on teacher burnout is weaker when teachers' agility is high rather than low.

(ii) H2b: the negative efficacy of SRTS on teacher burnout is weaker when teachers' agility is high rather than low.

2.3. The Moderating Effect of LMXD. Leader-member exchange quality differentiation (LMXD) was regarded as the extent of differentiation to which superiors develop distinct quality relationships with their staff [38]. A low LMXD value means a favorable leader-member relationship and a crucial job resource [39]. Prior studies report evidence that LMXD generates negative mood, for instance, distrust or disgust [40], group conflict [39], poor coordination [41], and assistance [42] from both leaders and colleagues.

A high LMXD value further strengthens the adverse effect of stress on job burnout. Firstly, when LMXD is high, for the relationship boundaries, it is unlikely for some teachers to receive resources and leader support [43], yet they receive passive information regarding role differentiation [44]. Thus, for those teachers who are suffering from role stress, it is more difficult to get out of their own role dilemma and to make a right decision. Secondly, when LMXD is high, it is more difficult for some teachers to obtain critical help and support from leaders or other teachers who might have been proficient at some cutting-edge education-related technologies [45], and thus they might fell more insecure.

Drawing on the JD-R model, we propose that the presence of differentiation in the relationship quality with supervisors will strengthen security-related role stress and technostress in aggravating teacher burnout. We attempt to explore the moderating effect of LMXD upon the link of SRRS and SRTS on teacher burnout. Based on the above agreement, when LMXD is high, SRRS and SRTS are more salient in burnout. Therefore, we propose that (i) H3a: compared with being low, the negative effect of SRRS on job burnout is more salient when LMXD is high.

(ii) H3b: compared with being low, the negative effect of SRTS on job burnout is more salient when LMXD is high.

\section{Methodology}

3.1. Sample and Data Collection. Our research sample frame came from high educational teachers located in China, whose majors are economics, management, engineering, science, philosophy, and literature. To test the hypotheses, we integrated some previously validated items and designed an original questionnaire. With the assistance of some university pro vice-chancellors, in charge of teaching and learning, we conducted in-depth interviews about job burnout with some departmental director and teachers, respectively. Based on the proceeding literature review and field interviews, we redesigned and modified our questionnaire.

Data collection involves two kinds, an online survey and an offline survey. First, we emailed electronic questionnaires to 524 teachers directly, and we received 56 feedbacks. Table 1 presents the profile of the sample. Secondly, with the support of some pro vice-presidents, we effectively adopted the on-site questionnaire distribution and collection. We collected 243 valid questionnaires of 400 distributed questionnaires, of which 28 were removed for being incomplete. Finally, we got 271 samples, with response rate of $28.3 \%$.

3.2. Measures. To validate the conceptual model, our study conducted an empirical investigation and developed the survey instrument in three steps. First, we adapted the measures from preceding studies and then translated the English questionnaire into Chinese while assuring conceptual precision [46]. Second, we asked three academic researchers with expertise in high education research to evaluate the questionnaire for questionnaire flow, design, and content validity. Third, we pilot-tested the questionnaire with 20 teachers and revised the survey instrument based on the feedback received.

3.2.1. Job Burnout. We measured job burnout with 9 items adapted from Chong et al. [6, 47], which is regarded as a series of negative mental experiences from chronic exposure to organizational stress. Example items included "I sense burned out from my work."

3.2.2. Technostress and Role Stress. We adopted scales from Hwang and Cha [20] to measure SRRS and SRTS [20]. SRRS was measured with 8 items, which is associated with workers' response to the situations where multiple roles are provided [20]. Examples included "I often receive assignments without adequate resources and materials to execute them." SRRS was defined as the complexity or uncertainty of education-related technology which induce teacher mental 
TABLe 1: Sample demographic $(N=271)$.

\begin{tabular}{lcc}
\hline & $N$ & Percentage (\%) \\
\hline Gender & & 28.4 \\
Male & 194 & 71.6 \\
Female & & 32.8 \\
Age & 89 & 42.8 \\
$20-30$ & 116 & 17.7 \\
$30-40$ & 48 & 5.9 \\
$40-50$ & 16 & 0.7 \\
$50-60$ & 2 & 7.0 \\
$\geq 60$ & & 30.3 \\
Education (Edu) & 19 & 52.4 \\
Below bachelor & 82 & 10.3 \\
Bachelor & 142 & 28 \\
Master & & \\
Doctor & 72 & 38.0 \\
Academic title (Acat) & 103 & 25.1 \\
Research assistant & 68 & 10.3 \\
Lecturer & 28 & \\
Associate professor & & \\
Professor & 41 & 84.9 \\
Overseas learning experience (Ole) & 230 & \\
Yes & & \\
No & &
\end{tabular}

pressure [26]. Example items included "I am forced by education-related technology to work much faster than before."

3.2.3. $L M X D$. We measured LMXD adapted from Chiniara and Bentein [38] which was evaluated for 3 items on the degree of differentiation of the exchange quality between superiors and their staff $[38,42]$. Examples include "Some departmental members have a positive working relationship with my leader while other team members do not."

3.2.4. Teacher Agility. We measured the teacher agility adapted from Pitafi et al. [34], which was assessed for 15 items on the capability of a teacher to respond and accommodate themselves to variation rapidly and correctly [34]. Examples include "I search for the chances to improve myself at my work."

\section{Result}

4.1. Construct Validity. We applied SPSS 21 and Lisrel in our study. Our CFA is to evaluate construct validity, and its results revealed that the measurement model fits the data well as advised $\left(c^{2} / \mathrm{d} f=2347.25 / 1016=2.31, \quad \mathrm{CFI}=0.94\right.$, $\mathrm{IFI}=0.94, \mathrm{NNFI}=0.93$, RMSEA $=0.07$ ). All item loadings were statistically significant. Meanwhile, the value of Cronbach's $\alpha$ and CR were all higher than 0.7 . The results of our research further showed good convergent validity and discriminant validity as well, because all values of the square root of the average variances extracted exceeded the thresholds of 0.70 [48] and were higher than the correlations with other constructs [49] (see Table 2). Therefore, in our study, our measures have appropriate reliability and validity.
4.2. Common Method Bias. We conducted one post hoc test to alleviate common method bias. The results of Harman's single-factor test displayed the first factor only contributed to 19.18 percent of the total variance, indicating a lack of evidence of common method bias. Moreover, the singlefactor model showed unacceptable fit indices $\left(c^{2} /\right.$ $\mathrm{d} f=1130.88 / 170=6.65, \mathrm{CFI}=0.79, \mathrm{IFI}=0.79, \mathrm{NNFI}=0.77$, RMSEA $=0.19$, SRMR $=0.12$ ), which were worse than that of our measurement model. Hence, common method bias was not likely to become a major issue.

4.3. Hypothesis Testing. To test the hypotheses in our study, we applied hierarchical regression because it is a usual way recommended to measure moderating effects. In order to reduce concerns of multicollinearity, we standardized all hypothesized variables. The results showed that multicollinearity was not a serious issue because all variance inflation factors (VIF) are less than 7, which is well below the acceptable maximum cutoff value of 10 [50].

In $\mathrm{H} 1 \mathrm{a}$ and $\mathrm{H} 1 \mathrm{~b}$, we anticipated that role stress and technostress associate positively to teacher burnout. Model 2 , in Table 3, indicated that role stress $(\beta=0.46, p<0.001$, $0.000)$ and technostress $(\beta=0.17, p<0.01,0.005)$ both have a significant effect on teacher burnout (see Figure 1). Moreover, compared to technostress, role stress exerted a more salient impact on teacher burnout. Therefore, H1a and $\mathrm{H} 1 \mathrm{~b}$ were both supported (see Figure 1).

$\mathrm{H} 2 \mathrm{a}$ and $\mathrm{H} 2 \mathrm{~b}$ anticipated the significant moderating impact of teacher agility upon the connection between security-related stress and teacher burnout. We predicted that teacher agility would weaken the effectiveness of role stress in constraining teacher burnout in $\mathrm{H} 2 \mathrm{a}$. On the contrary, the regression results indicated that the interactions of teacher agility with SRRS aggravating teacher burnout $(\beta=0.18$, 
TABLE 2: Descriptive statistics and correlations.

\begin{tabular}{|c|c|c|c|c|c|c|c|c|c|c|}
\hline Variable & 1 & 2 & 3 & 4 & 5 & 6 & 7 & 8 & 9 & 10 \\
\hline 1. JB & - & & & & & & & & & \\
\hline 2. TS & 0.36 & 0.79 & & & & & & & & \\
\hline 3. RS & 0.54 & 0.46 & 0.77 & & & & & & & \\
\hline 4. LMXD & -0.21 & -0.06 & -0.1 & 0.87 & & & & & & \\
\hline 5. EA & -0.10 & 0.22 & 0.20 & 0.16 & 0.82 & & & & & \\
\hline 6. Gender ${ }^{a}$ & 0.08 & -0.14 & -0.03 & 0.08 & -0.04 & - & & & & \\
\hline 7. Age $^{a}$ & 0.02 & 0.04 & -0.04 & -0.11 & -0.04 & 0.29 & - & & & \\
\hline 8. $\mathrm{Edu}^{a}$ & 0.06 & 0.02 & 0.01 & 0.01 & 0.01 & 0.27 & 0.34 & - & & \\
\hline 9. Title $^{a}$ & 0.08 & -0.02 & -0.02 & 0.02 & -0.05 & 0.32 & 0.60 & 0.53 & - & \\
\hline 10. $\operatorname{Exp}^{a}$ & 0.01 & 0.08 & -0.07 & 0.16 & 0.03 & 0.17 & 0.13 & 0.24 & 0.35 & - \\
\hline $\mathrm{M}$ & 3.00 & 3.41 & 3.23 & 1.71 & 3.82 & 0.28 & 1.99 & 2.66 & 2.19 & 0.15 \\
\hline SD & 0.59 & 0.51 & 0.65 & 0.68 & 0.57 & 0.45 & 0.90 & 0.76 & 0.95 & 0.36 \\
\hline
\end{tabular}

Note. The diagonal elements (i.e., italic values) are the square roots of average variances extracted (AVEs). The absolute value of the correlations above 0.14 is statistically significant at $p<0.05$ (two-tailed tests). ${ }^{a}$ Dummy variable.

TABLE 3: Hierarchical regression results.

\begin{tabular}{|c|c|c|c|c|}
\hline & \multicolumn{4}{|c|}{ DV: teacher burnout } \\
\hline & Model 1 & Model 2 & Model 3 & Model 4 \\
\hline Security-related technostress (SRTS) & & $0.17^{*}$ & $0.20^{* * *}$ & $0.21^{* * *}$ \\
\hline Security-related role stress (SRRS) & & $0.46^{* * *}$ & $0.48^{* * *}$ & $0.40^{* * *}$ \\
\hline LMXD & & & $-0.13^{* *}$ & $-0.17^{* *}$ \\
\hline Teacher agility (TA) & & & $-0.21^{* * *}$ & $-0.14^{* *}$ \\
\hline SRTS $\times$ LMXD & & & & -0.08 \\
\hline SRRS $\times$ LMXD & & & & $0.15^{*}$ \\
\hline SRTS $\times$ TA & & & & 0.02 \\
\hline $\mathrm{SRRS} \times \mathrm{TA}$ & & & & $0.18^{* *}$ \\
\hline Gender & 0.07 & 0.10 & $0.12^{*}$ & $0.11^{*}$ \\
\hline Age & -0.06 & -0.05 & -0.07 & -0.09 \\
\hline Education & 0.01 & -0.01 & -0.01 & 0.02 \\
\hline Academic title & 0.10 & 0.10 & 0.08 & 0.12 \\
\hline Experience & -0.04 & -0.02 & 0.01 & -0.03 \\
\hline $\mathrm{R} 2$ & -0.01 & 0.30 & 0.38 & 0.41 \\
\hline$\Delta \mathrm{R} 2$ & & 0.31 & 0.07 & 0.04 \\
\hline$F$ & 6.82 & $17.828^{* * *}$ & $18.428^{* * *}$ & $15.348^{* * *}$ \\
\hline$\Delta F$ & & $59.933^{* * *}$ & $14.243^{* * *}$ & $5.536^{* * *}$ \\
\hline
\end{tabular}

Note. $^{*} p<0.05 ;{ }^{* *} p<0.01 ;{ }^{* * *} p<0.001$; All tests are two-tailed. $(N=271)$

$p<0.05,0.03$ ), which fails to support H2a. Figure 2 reveals that role stress has stronger negative effects on teacher burnout when there is high $(\beta=0.61, p<0.001,0.000)$ than when there is low teacher agility $(\beta=0.48, p<0.001,0.000)$. In $\mathrm{H} 2 \mathrm{~b}$, although we predicted that teacher agility would weaken the effectiveness of technostress in suppressing teacher burnout, the regression result shows their interactions between teacher agility with SRTS on teacher burnout is not significant $(\beta=0.02, p>0.05,0.80)$, which fails to support $\mathrm{H} 2 \mathrm{~b}$.

$\mathrm{H} 3 \mathrm{a}$ and $\mathrm{H} 3 \mathrm{~b}$ anticipated a positive and significant moderating impact of LMXD upon the connection between role stress, technostress, and teacher burnout. The interaction between LMXD and role stress on teacher burnout is significant $(\beta=0.15, p<0.05,0.03$; see Table 3 , Model 4$)$, supporting H3a. Model 4, in Table 3, showed higher levels of LMXD strengthening the negative effects of role stress on teacher burnout, in support of $\mathrm{H} 3 \mathrm{a}$. Figure 3 reveals that role stress has stronger negative effects on teacher burnout when there is high LMXD $(\beta=0.53, p<0.001,0.000)$ than when there is low LMXD $(\beta=0.47, p<0.001,0.000)$. In H3b, although we predicted that LMXD would strengthen the efficacy of technostress on teacher burnout, the regression result showed that interaction between LMXD and SRTS on teacher burnout is not significant $(\beta=-0.08, p<0.05,0.24)$, which fails to support $\mathrm{H} 3 \mathrm{~b}$.

\section{Discussion and Implication}

5.1. Theoretical Implications. Teacher occupational burnout and stress have attracted attention from theoretical research and management practice, complicating social educational management research $[14,19]$ and setting higher requirements for the competencies of educational administrators [10]. Although there is widespread recognition of the role of stress, including role stress and technostress, in suppressing teacher burnout, the influences of the leader-member relationship quality and teacher subjective initiative in shaping 


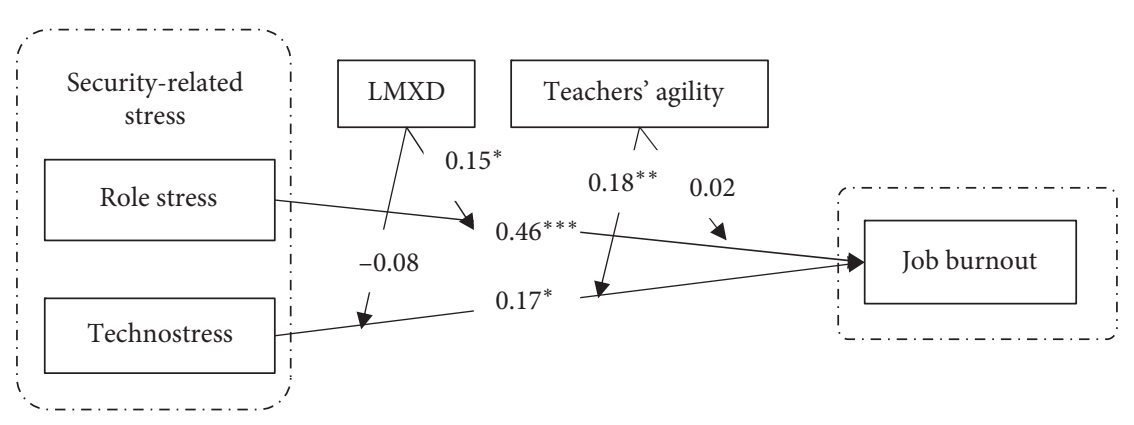

Figure 1: Path analysis of the research model. ${ }^{*} p<0.05 ;{ }^{* *} p<0.01 ;{ }^{* * *} p<0.001$;

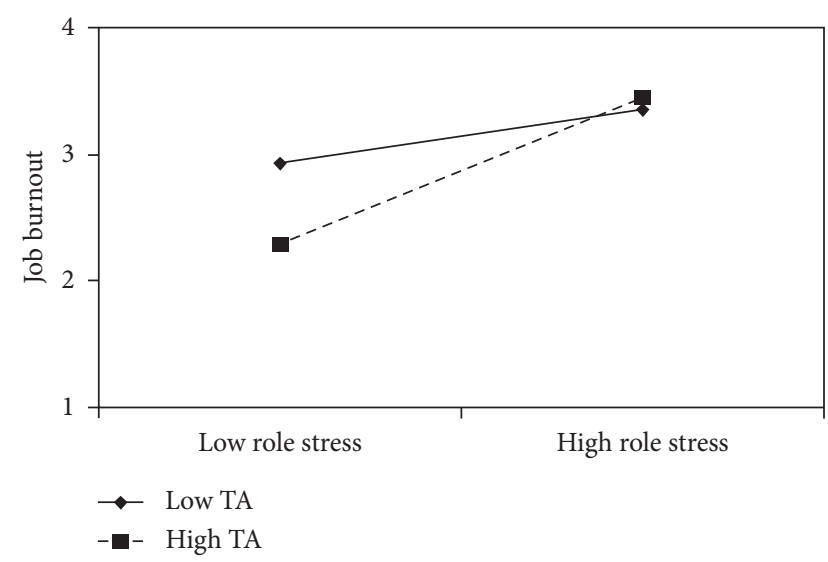

FIGURE 2: Role stress and teacher agility. The moderating effect of teacher agility on role stress-job burnout link.

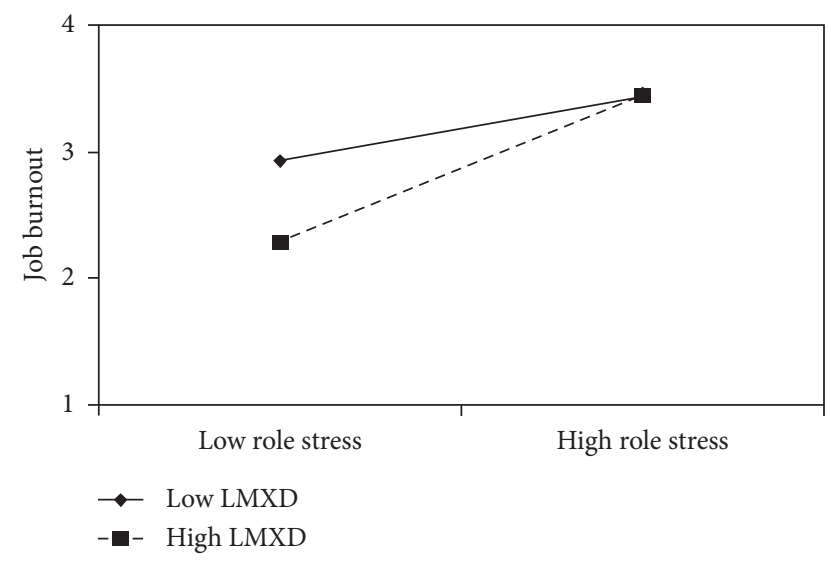

FIgUre 3: Role stress and LMXD. The moderating effect of LMXD on role stress-job burnout link.

their roles remain underexplored. With a survey of 271 teacher samples in China, we found that role stress plays a stronger role in deteriorating teacher burnout than technostress. LMXD enhances role stress in alleviating job burnout. What is surprising and interesting is that teacher agility also worsens job burnout, which is distinct from what we anticipated above. These findings make several contributions to the education management literature.
First, we provided a leadership contingent view of education management by explicating the moderating role of leader-member exchange quality differentiation. Some researches center on the impact of superior leadership $[14,45]$, but our study represents the first trial to investigate how the relationship of SRRS and SRTS and teacher burnout vary with different levels of leader-member exchange differentiation. When LMXD is high [44], role stress turns more effective in irritating teacher occupational burnout, because an unequal working situation restrains to pursue necessary resources imaginable for university teachers and consequently worsens the level of burnout.

Second, our study enriches the contingent view of JD-R by accounting for different levels of teacher agility. Unlike LMXD, teacher agility varies from person to person $[21,43,45]$. Perhaps most of teachers may make wrong efforts for the lack of appropriate supervision and instruction. Our findings show that role stress has a more salient role in teacher burnout when the level of agility is high for aggravating teacher burnout. Our studies also discovered that the interplay of teacher agility with technostress has a nonsignificant effect on teacher burnout, perhaps because teachers may not be able to overcome technical obstacles only with their own endeavour [25]. Our findings extend prior literature by showing that teacher agility may worsen teacher burnout rather than restrict it.

5.2. Practical Implications. Our study provides several guidelines for practitioners of educational management. Firstly, to lighten the negative efficacy, educational managers should attach emphasis on security-related stress and ought to take effective measures to reduce the adverse effect. Security-related stress, including role stress and technostress, both have a significant negative implication on job burnout. Secondly, role stress has a more salient negative influence than technostress does, especially when LMXD is high. University administrators should prioritize teachers' confusion regarding their role requirements, particularly when leader-member relationship quality is low. However, when teachers are stuck in the technostress, if universities try to optimize the leader-member relationship, the results may disappoint them.

Our findings also have important implications for teachers themselves. Some teachers are struggling from security-related stress [29], such as a large workload, role 
conflict or ambiguity, education-related technology complexity, and leader-member exchange relationship, all of which cause psychological and physical passive and exhaustion perception toward work [23]. Our finding confirms stress as a direct cause of job burnout among teachers. Thus, teachers shall take both role stress and technostress seriously and actively [51]; otherwise, they might lose their enthusiasm for educational research and teaching and suffer severe job burnout. As our findings indicate, teachers should attach more emphasis to develop their own agility toward the correct direction. Teachers who have been stuck in role stress may not be clear about what they can or should do. Thus, the more efforts they make, perhaps the more confused they get, and the less progress they will make naturally.

5.3. Limitation and Future Research. Our research consists of two limitations. The impact of agility may vary with time and person. Firstly, the cross-sectional data cannot support us to test the causal link in our concept model. Longitudinal studies might capture the dynamic effects of teacher agility on suppressing the negative impacts between security-related stress and job burnout. Secondly, we gathered data by the virtue of convenient sample methods, and thus we cannot collect data of teachers who are experiencing a distinct degree of security-related stress. Teachers with different experiences show different levels of agility, so the interaction of teacher agility with security-related stress displays distinct characteristics and effects. The teacher's capability to apply education-related technology and getting support from their superiors vary tremendously with development levels of the university and the local economy development [25]. We could conduct stratified sampling studies with large-scale participants in the future in order to gain more sound conclusions and thorough understanding.

\section{Data Availability}

The data used to support the findings of this study are available from the corresponding author upon request.

\section{Conflicts of Interest}

The authors declare no conflicts of interest.

\section{Acknowledgments}

This study was supported by three Key Project Funds from Anhui Education Ministry (no. SK2019A0730, no. SK2019A0749, and no. gxyqZD2016383). The authors thank University of Science and Technology of China for providing laboratory and test system for this study.

\section{References}

[1] E. d. Mol, V. T. Ho, and J. M. Pollack, "Predicting entrepreneurial burnout in a moderated mediated model of job fit," Journal of Small Business Management, vol. 56, no. 3, pp. 392-411, 2018.

[2] M. P. Leiter and C. Maslach, "The social context of burnout," International Journal of Psychology, vol. 51, p. 732, 2016.
[3] X. Wu, H. K. Kwan, L.-Z. Wu, and J. Ma, "The effect of workplace negative gossip on employee proactive behavior in China: the moderating role of traditionality," Journal of Business Ethics, vol. 148, no. 4, pp. 801-815, 2015.

[4] H. S. Jung, H. H. Yoon, and Y. J. Kim, "Effects of culinary employees' role stress on burnout and turnover intention in hotel industry: moderating effects on employees' tenure," The Service Industries Journal, vol. 32, no. 13, pp. 2145-2165, 2012.

[5] C. Maslach and M. P. Leiter, "New insights into burnout and health care: strategies for improving civility and alleviating burnout," Medical Teacher, vol. 39, no. 2, pp. 160-163, 2017.

[6] V. K. Chong, G. S. Monroe, and S. Cahan, "The impact of the antecedents and consequences of job burnout on junior accountants' turnover intentions: a structural equation modelling approach," Accounting \& Finance, vol. 55, no. 1, pp. 105-132, 2015.

[7] T. Fagarty, J. Singh, G. K. Rhoads, and R. K. Moore, “Antecedents and consequences of burnout in accounting beyond the role stress model," Behavioral Research in Accounting, vol. 12, 2000.

[8] R. Agcam and M. P. Babanoglu, "An investigation on EFL teachers' attitude toward teaching profession," Higher Education Studies, vol. 6, no. 3, p. 21, 2016.

[9] X. Wang, S. C. Tan, and L. Li, "Technostress in university students' technology-enhanced learning: an investigation from multidimensional person-environment misfit," Computers in Human Behavior, vol. 105, p. 106208, 2020.

[10] Y. H. Lee, "Emotional labor, teacher burnout, and turnover intention in high-school physical education teaching," European Physical Education Review, vol. 25, no. 1, pp. 236-253, 2017.

[11] Y.-N. Cho, B. N. Rutherford, S. B. Friend, G. A. Hamwi, and J. Park, "The role of emotions on frontline employee turnover intentions," Journal of Marketing Theory and Practice, vol. 25, no. 1, pp. 57-68, 2016.

[12] G. M. Alarcon, "A meta-analysis of burnout with job demands, resources, and attitudes," Journal of Vocational Behavior, vol. 79, no. 2, pp. 549-562, 2011.

[13] M.-T. Tsai and H. Ya-Ti, "A resource-based perspective on retention strategies for nurse epidemiologists," Journal of Advanced Nursing, vol. 61, no. 2, pp. 188-200, 2008.

[14] S. Mo and J. Shi, "Linking ethical leadership to employee burnout, workplace deviance and performance: testing the mediating roles of trust in leader and surface acting," Journal of Business Ethics, vol. 144, no. 2, pp. 293-303, 2015.

[15] Y. Wang, A. Ramos, H. Wu et al., "Relationship between occupational stress and burnout among Chinese teachers: a cross-sectional survey in Liaoning, China," International Archives of Occupational and Environmental Health, vol. 88, no. 5, pp. 589-597, 2015.

[16] E. Oberle and K. A. Schonert-Reichl, "Stress contagion in the classroom? The link between classroom teacher burnout and morning cortisol in elementary school students," Social Science \& Medicine, vol. 159, pp. 30-37, 2016.

[17] E. M. Skaalvik and S. Skaalvik, "Teacher self-efficacy and teacher burnout: a study of relations," Teaching and Teacher Education, vol. 26, no. 4, pp. 1059-1069, 2010.

[18] S. C. Srivastava, S. Chandra, and A. Shirish, "Technostress creators and job outcomes: theorising the moderating influence of personality traits," Information Systems Journal, vol. 25, no. 4, pp. 355-401, 2015.

[19] C. Maslach, M. P. Leiter, and S. E. Jackson, "Making a significant difference with burnout interventions: researcher and 
practitioner collaboration," Journal of Organizational Behavior, vol. 33, no. 2, pp. 296-300, 2012.

[20] I. Hwang and O. Cha, "Examining technostress creators and role stress as potential threats to employees' information security compliance," Computers in Human Behavior, vol. 81, pp. 282-293, 2018.

[21] D. Xanthopoulou, A. B. Bakker, E. Demerouti, and W. B. Schaufeli, "The role of personal resources in the job demands-resources model," International Journal of Stress Management, vol. 14, no. 2, pp. 121-141, 2007.

[22] A. Bakker, E. Demerouti, and W. Schaufeli, "The job demands-resources model of burnout," Journal of Applied Psychology, vol. 86, no. 3, pp. 499-512, 2001.

[23] M. Yankelevich, A. Broadfoot, J. Z. Gillespie, M. A. Gillespie, and A. Guidroz, "General job stress: a unidimensional measure and its non-linear relations with outcome variables," Stress and Health, vol. 28, no. 2, pp. 137-148, 2012.

[24] J.-B. Liu, J. Zhao, J. Min, and J. D. Cao, "On the Hosoya index of graphs formed by a fractal graph," Fractals-Complex Geometry Patterns and Scaling in Nature and Society, vol. 27, no. 8, pp. 19-35, 2019.

[25] Y. Dong, C. Xu, C. S. Chai, and X. Zhai, "Exploring the structural relationship among teachers' technostress, technological pedagogical content knowledge (TPACK), computer self-efficacy and school support," The Asia-Pacific Education Researcher, vol. 29, no. 2, p. 147, 2019.

[26] S. Zhang, R. C.-W. Kwok, P. B. Lowry, Z. Liu, and J. Wu, "The influence of role stress on self-disclosure on social networking sites: a conservation of resources perspective," Information \& Management, vol. 56, no. 7, p. 103147, 2019.

[27] C.-C. Yang, C.-W. Fan, K.-M. Chen, S.-C. Hsu, and C.-L. Chien, "As a happy kindergarten teacher: the mediating effect of happiness between role stress and turnover intention," The Asia-Pacific Education Researcher, vol. 27, no. 6, pp. 431-440, 2018.

[28] J. Peng, D. Li, Z. Zhang et al., "How can core self-evaluations influence job burnout? The key roles of organizational commitment and job satisfaction," Journal of Health Psychology, vol. 21, no. 1, pp. 50-59, 2016.

[29] X. Yu, P. Wang, X. Zhai, H. Dai, and Q. Yang, "The effect of work stress on job burnout among teachers: the mediating role of self-efficacy," Social Indicators Research, vol. 122, no. 3, pp. 701-708, 2014.

[30] F. O. Pineida, "Competencies for the 21st century: integrating ICT to life, school and economical development," Procedia-Social and Behavioral Sciences, vol. 28, pp. 54-57, 2011.

[31] S. Krishnan, "Personality and espoused cultural differences in technostress creators," Computers in Human Behavior, vol. 66, pp. 154-167, 2017.

[32] T. S. Ragu-Nathan, M. Tarafdar, B. S. Ragu-Nathan, and Q. Tu, "The consequences of technostress for end users in organizations: conceptual development and empirical validation," Information Systems Research, vol. 19, no. 4, pp. 417-433, 2008.

[33] S. Alavi, D. A. Wahab, N. Muhamad, and B. Arbab Shirani, "Organic structure and organisational learning as the main antecedents of workforce agility," International Journal of Production Research, vol. 52, no. 21, pp. 6273-6295, 2014.

[34] A. H. Pitafi, H. Liu, and Z. Cai, "Investigating the relationship between workplace conflict and employee agility: the role of enterprise social media," Telematics and Informatics, vol. 35, no. 8, pp. 2157-2172, 2018.

[35] D. Cumming, I. Filatotchev, J. Reinecke, and G. Wood, "New investor categories, agility and HRM: the case of Sovereign
Wealth Funds," Human Resource Management Review, vol. 30, no. 1, p. 100694, 2020.

[36] X. Wang and B. Li, "Technostress among university teachers in higher education: a study using multidimensional personenvironment misfit theory," Frontiers in Psychology, vol. 10, p. 1791, 2019.

[37] Y. J. Joo, K. Y. Lim, and N. H. Kim, "The effects of secondary teachers' technostress on the intention to use technology in South Korea," Computers \& Education, vol. 95, pp. 114-122, 2016.

[38] M. Chiniara and K. Bentein, "The servant leadership advantage: when perceiving low differentiation in leadermember relationship quality influences team cohesion, team task performance and service OCB," The Leadership Quarterly, vol. 29, no. 2, pp. 333-345, 2018.

[39] A. Yu, F. K. Matta, and B. Cornfield, "Is leader-member exchange differentiation beneficial or detrimental for group effectiveness? A meta-analytic investigation and theoretical integration," Academy of Management Journal, vol. 61, no. 3, pp. 1158-1188, 2018.

[40] R. C. Liden, B. Erdogan, S. J. Wayne, and R. T. Sparrowe, "Leader-member exchange, differentiation, and task interdependence: implications for individual and group performance," Journal of Organizational Behavior, vol. 27, no. 6, pp. 723-746, 2006.

[41] X.-P. Chen, W. He, and L.-C. Weng, "What is wrong with treating followers differently? The basis of leader-member exchange differentiation matters," Journal of Management, vol. 44, no. 3, pp. 946-971, 2015.

[42] C. Emery, J. E. Booth, G. Michaelides, and A. J. Swaab, "The importance of being psychologically empowered: buffering the negative effects of employee perceptions of leadermember exchange differentiation," Journal of Occupational and Organizational Psychology, vol. 92, no. 3, pp. 566-592, 2019.

[43] K. Lee, Y. J. Chae, and I. Shin, "Motivational antecedents of leader-member exchange differentiation: evidence from South Korea," Asia Pacific Journal of Management, vol. 33, no. 1, pp. 87-112, 2016.

[44] S. Auh, D. E. Bowen, C. Aysuna, and B. Menguc, "A search for missing links," Journal of Service Research, vol. 19, no. 3, pp. $260-275,2016$.

[45] C. H. Thomas and M. J. Lankau, "Preventing burnout: the effects of LMX and mentoring on socialization, role stress, and burnout," Human Resource Management, vol. 48, no. 3, pp. 417-432, 2009.

[46] L. Poppo, K. Z. Zhou, and J. J. Li, "When can you trust "trust"? Calculative trust, relational trust, and supplier performance," Strategic Management Journal, vol. 37, no. 4, pp. 724-741, 2016.

[47] W. B. Schaufeli, M. P. Leiter, and C. Maslach, "Burnout: 35 years of research and practice," Career Development International, vol. 14, no. 3, pp. 204-220, 2009.

[48] C. E. Lance, M. M. Butts, and L. C. Michels, "The sources of four commonly reported cutoff criteria," Organizational Research Methods, vol. 9, no. 2, pp. 202-220, 2006.

[49] C. Fornell and D. F. Larcker, "Evaluating structural equation models with unobservable variables and measurement error," Journal of Marketing Research, vol. 18, no. 1, pp. 39-50, 1981.

[50] J. Neter, M. H. Kutner, C. J. Nachtsheim, and W. Wasserman, Applied Linear Statistical Models, Irwin, Chicago, IL, USA, 1996.

[51] C. Maier, S. Laumer, C. Weinert, and T. Weitzel, "The effects of technostress and switching stress on discontinued use of social networking services: a study of Facebook use," Information Systems Journal, vol. 25, no. 3, pp. 275-308, 2015. 